\title{
CONGENITAL CATARACTS, RENAL TUBULAR NECROSIS AND ENCEPHALOPATHY IN TWO SISTERS
}

\author{
BY \\ L. CROME*, SERGE DUCKETT and A. WHITE FRANKLIN \\ From The Fountain Hospital, Tooting, London, and St. Bartholomew's Hospital, London
}

(RECEIVED FOR PUBLICATION APRIL 16, 1963)

We present here an account of two infant sisters suffering from a congenital and, probably, inherited disease, the chief features of which were epilepsy, cataracts, renal tubular necrosis and an encephalopathy comprising micrencephaly, lack of myelination and cerebellar dysplasia. The condition resembles the so-called Marinesco-Sjögren syndrome and also the oculo-cerebro-renal (Lowe's) syndrome, although it may be quite distinct from each of these.

\section{The Family}

The family tree is illustrated in Fig. 1.

The brothers III 3 and III 4 married respectively two sisters, III 11 and III 8, who were also their first

* Part of the histological work was done with the aid of a grant by the National Society for Mentally Handicapped Children. cousins. The subjects of this report, IV 6 and IV 10 , are the daughters of III 4 and III 8. The five other children of this family are well. III 3 and IIl 11 have had two mentally retarded children, IV 3 and IV 4, and a healthy son, IV 5 . IV 3 , a girl aged 14 years, is $139 \mathrm{~cm}$. in height, the average for the age being $159.6 \mathrm{~cm}$. Her haemoglobin, blood urea, serum electrolytes, alkali reserve, and the serum alkaline phosphatase, calcium, creatinine and inorganic phosphate were all normal. No abnormal amino acids were detected by urine chromatography. A skull radiograph showed a normal sella turcica. The bone age in a radiograph of the wrist was estimated at 11 years. Both kidneys excreted contrast medium at five minutes with good concentration. No abnormality was demonstrated in the calyces, pelvis of either kidney or in the ureters and bladder. The creatinine clearance was $97 \mathrm{ml}$. per minute. The hydrogen ion excretion and ammonia synthesis were within normal limits. The only bio-

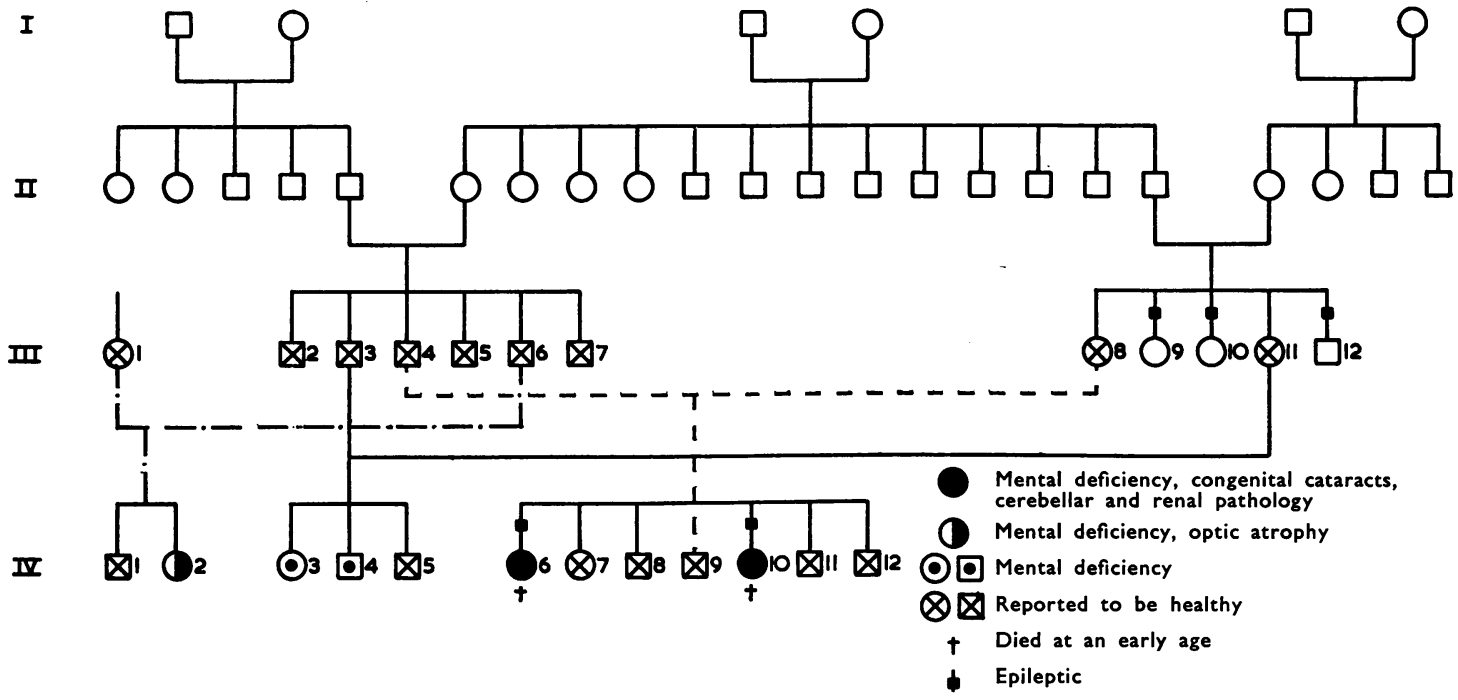

FIG. 1.-Family tree. 
chemical abnormality present was an increase in the serum $\alpha_{2}$ and $\beta$ globulins. The chromosomes of blood culture cells were normal in number. A third brother of III 3 and III 4, III 6 , has a healthy son and a mentally retarded but well-grown daughter, IV 2, with optic atrophy. Two maternal aunts and one maternal uncle of IV 6 and IV 10 have been treated for epilepsyIII 9, III 10 and III 12.

Case 1 (IV 6). The confinement took place prematurely after an accidental haemorrhage. The baby weighed $1.9 \mathrm{~kg}$. at birth, gaining about $0.4 \mathrm{~kg}$. in the next six weeks. It was noticed at 3 months that she did not look at objects and had nystagmus. She then began having epileptic attacks and when examined in hospital a diagnosis was made of lamellar cataracts, mental deficiency and epilepsy. At 5 months her head circumference measured $39.4 \mathrm{~cm}$., the normal for the age being about $41 \mathrm{~cm}$. She could not hold up her head, the plantar responses were extensor and she appeared to move her left hand less than the right. Her epileptic fits remained uncontrolled by treatment and she also had jerky movements of the extremities between fits. At 6 months she was admitted to St. Thomas's Hospital with status epilepticus. At that time the Wassermann reaction was negative; the cerebrospinal fluid was clear, containing 4 cells/c.mm., with protein, $120 \mathrm{mg}$./100 ml.; sugar, $46 \mathrm{mg}$. $/ 100 \mathrm{ml}$; ; and $\mathrm{NaCl}-690 \mathrm{mg} . / 100 \mathrm{ml}$. At 8 months she was readmitted in a semi-conscious state with flaccidity and twitching of the face and limbs. Her head circumference measured $39.8 \mathrm{~cm}$., the average normal for the age being $44 \cdot 7 \mathrm{~cm}$. with S.D. $\pm 1 \cdot 2$. The cerebrospinal fluid pressure was $120 \mathrm{~mm}$., with protein, $70 \mathrm{mg} . / 100 \mathrm{ml}$.; sugar, $85 \mathrm{mg} . / 100 \mathrm{ml}$.; and chlorides, $715 \mathrm{mg} . / 100 \mathrm{ml}$. The urine contained traces of albumin with a few red blood cells, some pus cells and casts. She died three days after admission.

Pathological Findings. The only gross changes recorded at autopsy were irregular lenticular opacities and some fatty change in the liver.

Histological Findings. The material made available for the present study comprised paraffin-embedded blocks of parts of cerebrum, brain-stem, cerebellum, several levels of the spinal cord, one half of an eye, the kidney, liver, adrenal, heart and thymus. Sections of the neural tissue were stained with haematoxylin and eosin, H.V.G., P.T.A.H. and by the Weil, Holzer, Penfield's and Glees Marsland methods. Unfortunately, it proved impossible to identify the precise topographical origin of some blocks. Moreover, these had been stored for 12 years before examination; the paraffin had crystallized and not enough tissue remained for re-embedding. This made detailed study difficult, and only the more unequivocal findings are presented below.

The chief changes in the central nervous system were widespread spongy breakdown of the grey and white matter, uneven neuronal degeneration and cerebellar dysplasia.

The meninges were normal. Many of the neurones in the cerebral cortex were surrounded by a clear zone of pericellular oedema, and the interstitial tissue was rarefied, the vacuolated spaces tending to coalesce into larger ragged cavities. Some of the larger neurones were compressed and distorted by the surrounding oedema. Rarefaction of the tissue was even more marked in the white matter of the centrum semiovale, where some of the cavities contained eosinophil, plasmalike homogeneous material. Only a minimum of myelination was present in the cerebral white matter, although axons were demonstrable by silver impregnation. Most of the white matter was rather acellular, but certain areas showed slight astrocytic and neuroglial hyperplasia. Some of the astrocytes were plump and fibre-forming. There was no appreciable accumulation of neutral fat. Many blood vessels seemed constricted, their perivascular spaces being greatly widened and reticulated by sparse glial fibrils (Fig. 2).

In general, similar but less severe neuronal and interstitial changes were present in all other parts of the central nervous system. The basal ganglia were relatively well preserved. A few calcified concretions were present close to the ventricular wall, and some debris of nuclear material were scattered through the tissue. The ependyma was well preserved and the choroid plexuses were normal. The brain-stem showed complete lack of myelination of the cortico-pontine and corticospinal fibres. The inferior olives were well preserved. Unfortunately, only one section of the cerebellum was available, and this did not include much of the white matter or any of the central nuclear formations. The cerebellar cortex showed, however, an almost total loss of Purkinje cells, some proliferation of Bergmann glia and oedematous cleavage (lamina dissecans) at the junction of the molecular and granular layers (Fig. 3). The granular layer seemed also hypoplastic in some of the folia. The white matter showed spongy degeneration and marked deficiency of myelination. A gliotic focus was present in one area. It extended from the surface through the cerebellar cortex well into the white matter, and consisted of densely arranged fibrous astrocytes and many iron-laden phagocytes. This lesion was interpreted as an old haemorrhage.

The spinal cord also presented considerable lack of myelination of the lateral and anterior columns. Status spongiosus was present in the white matter and many of the neurones in the grey matter were severely distorted by pericellular oedema.

The Eye. The stained section of the eye measured $1.7 \times 1.4 \mathrm{~cm}$. at its widest perimeter. The eye had been needled during life. The cornea and conjunctiva were normal. The lens was flattened and distorted in shape. Its central part was almost entirely missing. The anterior capsule was torn and the edges around the missing part formed synechiae extending to the posterior surface of the iris. Many irregularly-shaped clefts, vacuoles and larger spaces were present in the remaining part of the lens. Most of these were situated around its centre where the tissue showed no evidence of lamellation. Some contained a reticulum of very fine eosinophil material, while many vacuoles were filled with a homogeneous, structureless and somewhat opaque substance. The retina, fragmented by histological processing, showed 


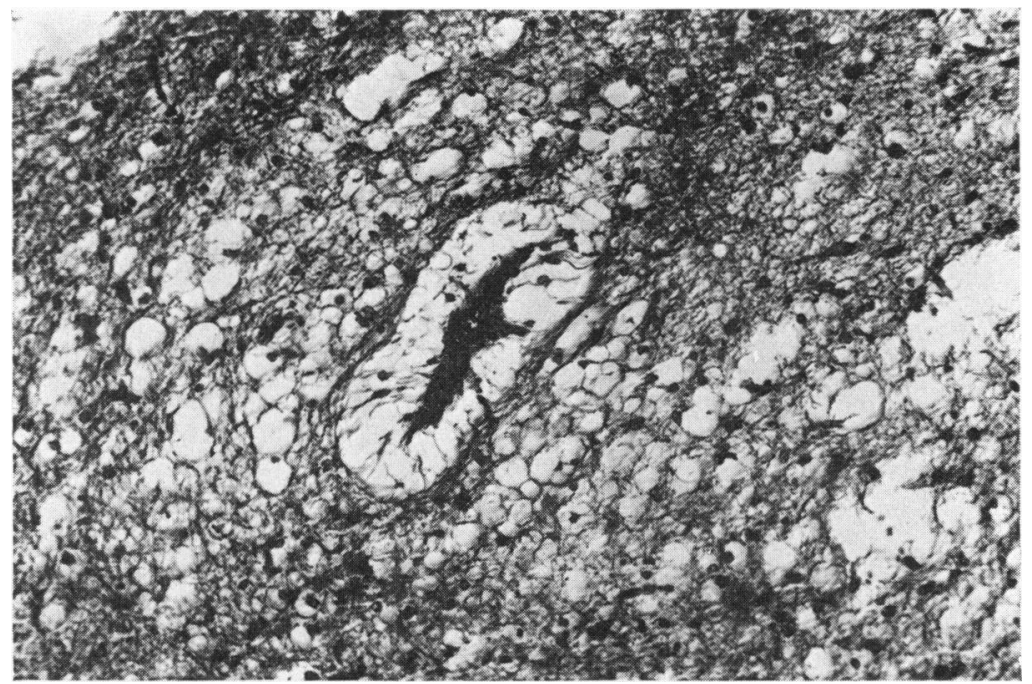

Fig. 2.-Case 1. Spongiosis of neural tissue and perivascular dilatation. (H. and E. $\times 200$.)

marked loss of the outer molecular layer with preservation of the nuclear layers and some suggestion of oedema which might have been an artefact of paraffin sectioning. Gliosis was present in the optic nerve.

The Kidney. This showed many necrotic foci in the boundary zone of the medulla (Fig. 4). These ranged in size up to about $1 \mathrm{~mm}$. in diameter, while the smallest consisted only of a necrotic zone in one or two neighbouring tubules and intervening tissue. The necrosis was accompanied by oedema and histiocytic proliferation.
The histiocytes had elongated rod-shaped or undulating, darkly-stained nuclei, and their cytoplasm contained phagocytosed granular, somewhat basophilic material. Some of these cells were very close to each other resembling multinucleate giant cells. Thin bundles of young connective tissue traversed some of the larger foci and formed capsules around them. Neighbouring tubules were often compressed by the lesions with resulting proximal dilatation. Some of the abnormal necrotizing tissue protruded into the lumina of these dilated tubules

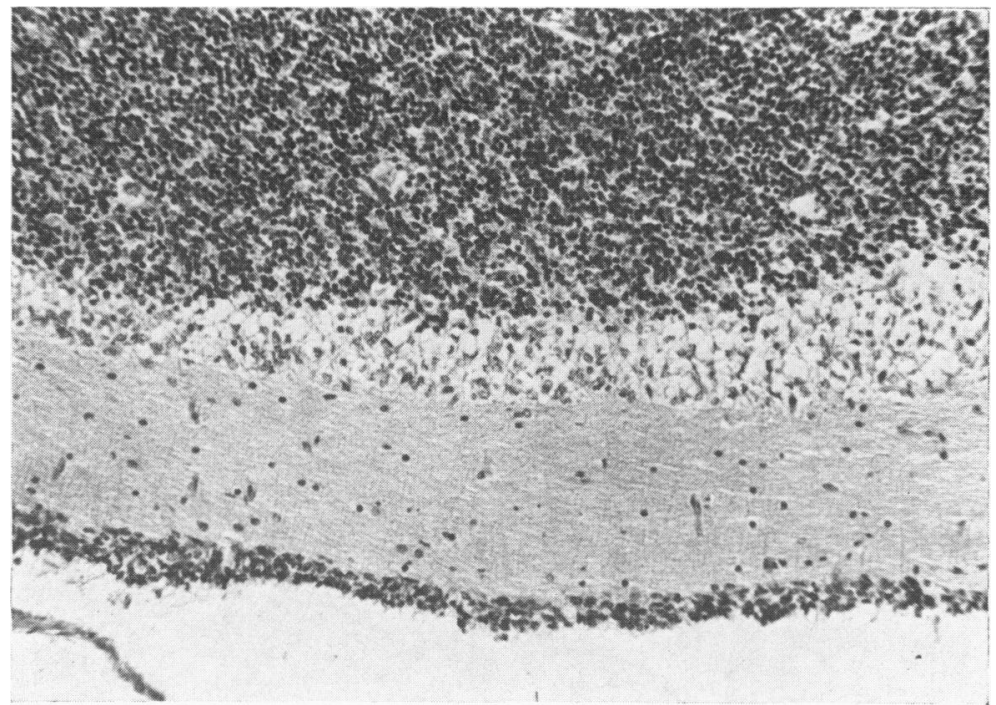

FIG. 3.-Case 1. Oedematous cleavage at junction of the molecular and granular cerebellar layers with proliferation of Bergmann glia and total absence of Purkinje cells. (H. and E. $\times 200$.) 


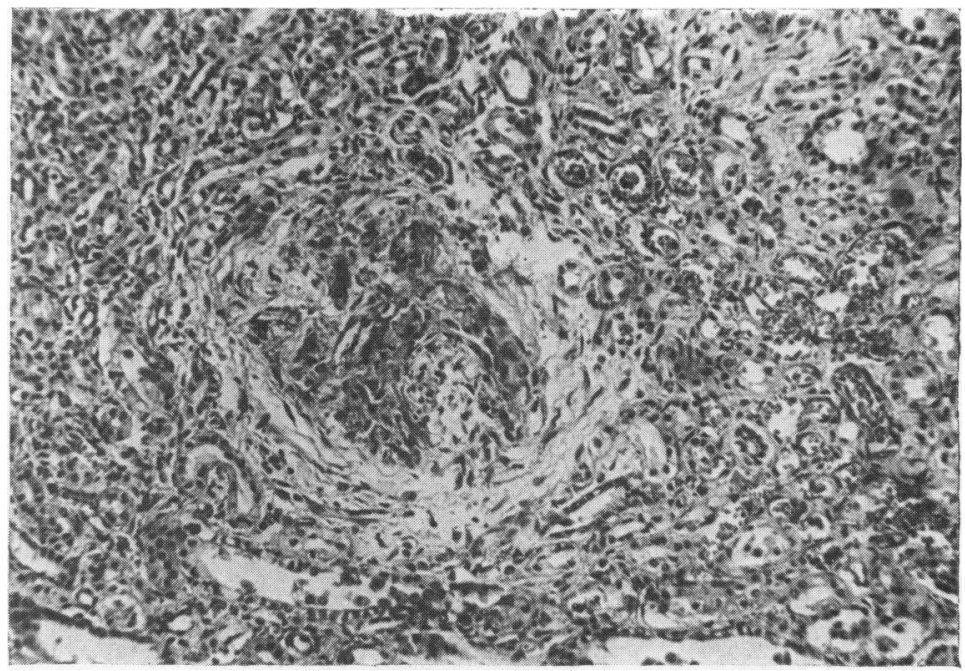

Fig. 4.-Case 1. Tubular necrosis in the boundary zone of the renal medulla. (H. and E. $\times 200$.)

as granular and cellular casts, and these were often surrounded by mucoid or plasma-like homogeneous material (Fig. 5). Many collecting tubules showed considerable, possibly autolytic, desquamation of epithelium. In the renal cortex, some glomeruli showed slight proliferation of the capsular epithelium, atrophy and oedema.

The lungs showed widespread focal collapse. Considerable oedema was present in the heart, and the liver showed marked cellular vacuolation. Some extramedullary haemopoiesis was present in the thymus. The adrenal was normal.

Case 2 (IV 10). This younger sister of Case 1 was born after a normal pregnancy and confinement, weighing $3.79 \mathrm{~kg}$. It was noticed a few days later that she shook her head excessively and had bilateral cataracts. At 6 weeks she had her first attack of grand mal. When

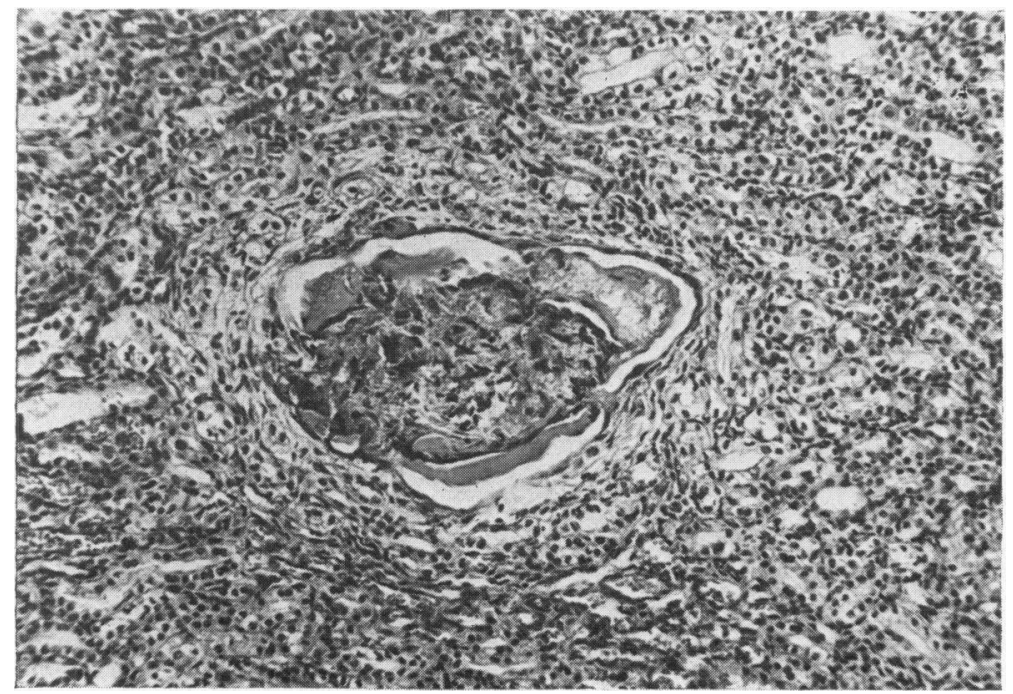

Fig. 5.-Case 1. Necrotic tubular tissue surrounded by mucus protruding into dilated tubules. (H. and $\mathrm{E}_{0} \times 200$.) 
admitted to St. Bartholomew's Hospital at 6 weeks, she rolled her head continuously. Her pupils were equal and did not react to light. The fundi could not be seen because of the cataracts. Her head circumference measured $36 \cdot 2 \mathrm{~cm}$., which is within the normal range. Her fits continued despite treatment. The skull radiograph was normal. The electroencephalogram showed an abnormally slow record with random bilateral epileptic discharges. The urine was normal, showed a normal pattern of amino acids on chromatography, and contained no galactose or phenylpyruvic acid. The Wassermann reaction was negative. The blood sugar was $116 \mathrm{mg} . / 100 \mathrm{ml}$; blood urea, $68 \mathrm{mg} . / 100 \mathrm{ml}$.; serum calcium, $11.4 \mathrm{mg} . / 100 \mathrm{ml}$; alkali reserve, $18 \cdot 9$ $\mathrm{mEq} / \mathrm{l}$. and serum potassium $6 \mathrm{mEq} / \mathrm{l}$. She died from pneumonia at 4 months. a lack of demarcation between their nuclear formations, and the internal capsule lacked its normal whiteness. The corpus callosum was very thin. The cerebellum and brain-stem (not weighed separately from the rest of the brain) presented no naked-eye abnormality. The haemopoietic system, the endocrine and the genital systems were normal.

\section{Histological Examination}

Central Nervous System. Neural tissue available for detailed examination consisted of horizontal blocks of the cerebrum and cerebellum with the brain-stem. Representative blocks of all available parts of the brain were embedded in celloidin and in paraffin, and stained as in Case 1. Frozen sections were used for fat staining.

The main changes were, as in Case 1, widespread lack of myelination, status spongiosus of the grey and white

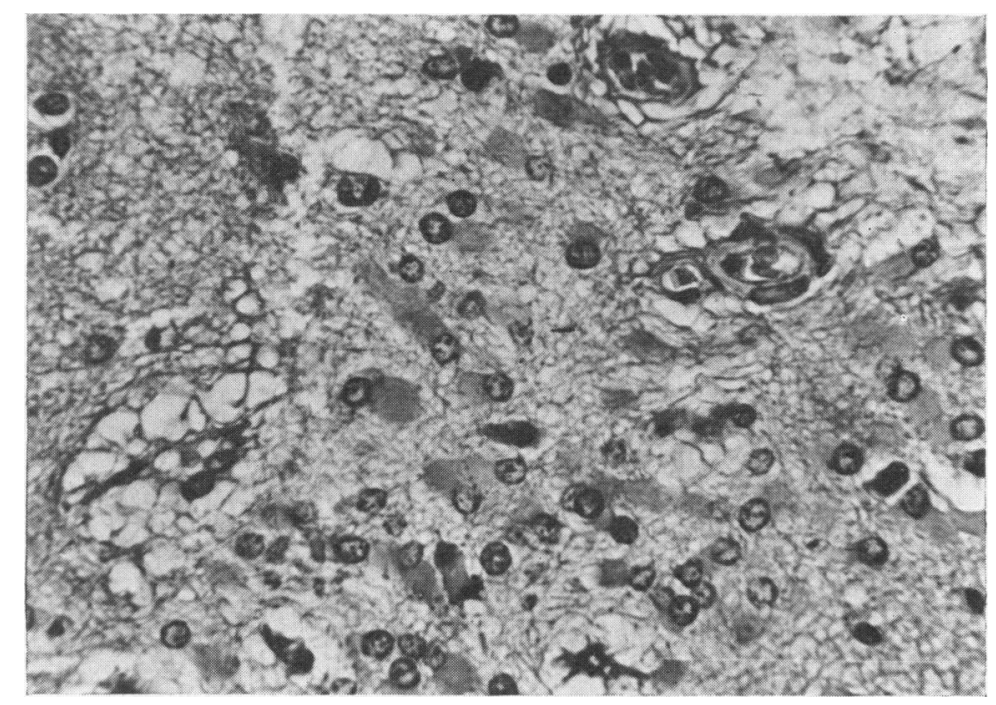

Fig. 6.-Case 2. Astrocytic proliferation in the white matter. (H. and E. $\times 400$.)

Autopsy. The baby was well nourished showing normal development for the age, except for a small cranium, which made her face seem rather pointed. The head circumference was not recorded. The anterior fontanelle was approximately $2 \mathrm{~cm}$. in diameter. Both lenses were opaque. Mucopus was present in the main bronchi, and there was bilateral basal bronchopneumonia, which was most advanced in the right lower lobe. The pericardial sac contained an excess of clear fluid. Otherwise the heart and main vessels were normal. The digestive tract was normal. The liver was somewhat fatty. The kidneys were rather soft, the left showing early 'suppurative pyelonephritis'. The mucosa of the bladder was slightly hyperaemic. The brain weighed $490 \mathrm{~g}$., the normal for the age being $540 \mathrm{~g}$. The coronal blocks presented deficiency of myelin; the centrum semiovale was slightly greyish, the basal ganglia showed matter, and loss of cerebellar Purkinje cells. The meninges over the cerebral cortex were oedematous. Over the brain-stem and at the base of the brain there was, in addition, considerable mobilization of meningocytes, some of which were phagocytic, containing globules of neutral fat and red blood corpuscles. Neurones throughout the central nervous system showed pericellular oedema, distortion of cellular outlines and central chromatolysis. There was some status spongiosus in the cerebral cortex, but this was not as marked as in Case 1. Some uneven subpial astrocytic proliferation was present in a few areas, particularly in the troughs of the sulci. The white matter showed more marked spongy lacunation and macro- and microglial proliferation (Fig. 6). Many fat-laden compound granular corpuscles were scattered diffusely through the tissue and concentrated around blood vessels (Fig. 7). Fine fat 


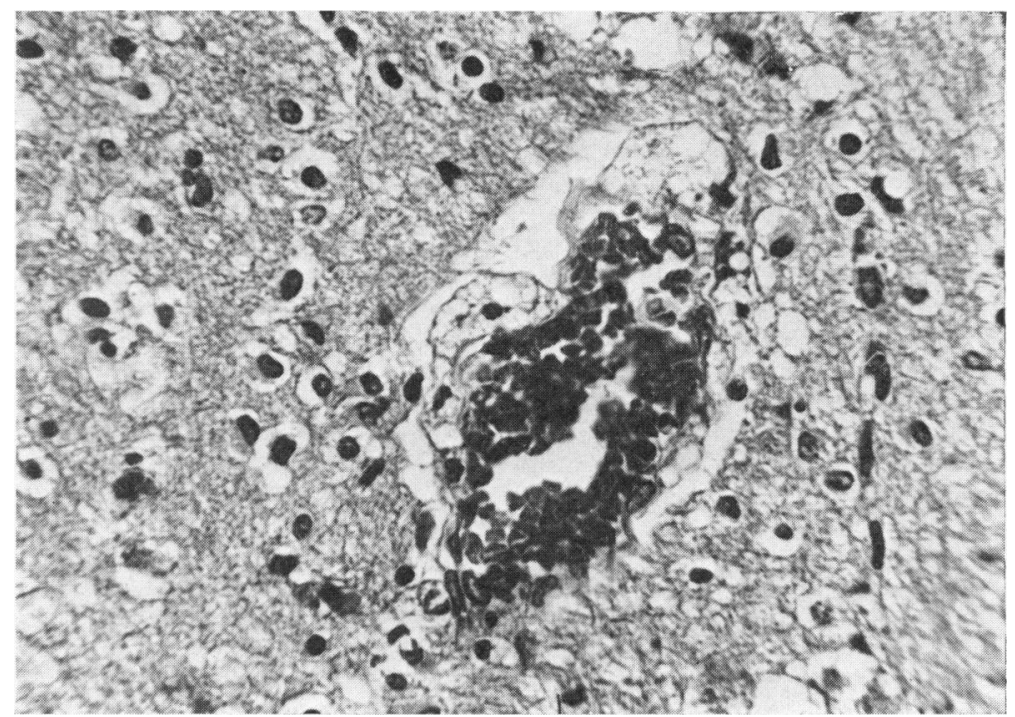

FIG. 7.-Case 2. Compound granular corpuscles in the perivascular space of a blood vessel. (H. and E. $\times 400$.)

particles were also present in astrocytes of the white and grey matter and in capillary endothelial cells. Perivascular spaces were often distended, some of these being sparsely or more densely cellular while others were reticulated by glial fibres (Fig. 8). There was an obvious lack of myelin throughout the cerebral white matter, but this was not as marked as in Case 1. The walls and surrounding tissue of many pre-capillaries and capillaries were impregnated with an eosinophil plasma-like substance, and the affected perivascular areas showed all gradations from normality to coagulative necrosis and partial dissolution and reticulation of the tissue (Fig. 9). The basal ganglia were relatively well preserved. The ependyma was flattened but intact everywhere, showing only a little, possibly autolytic, desquamation in a few areas.

Myelination in the brain-stem was deficient but, nevertheless, somewhat better developed than in Case 1. Thus, some myelinated fibres were present in the pyramids

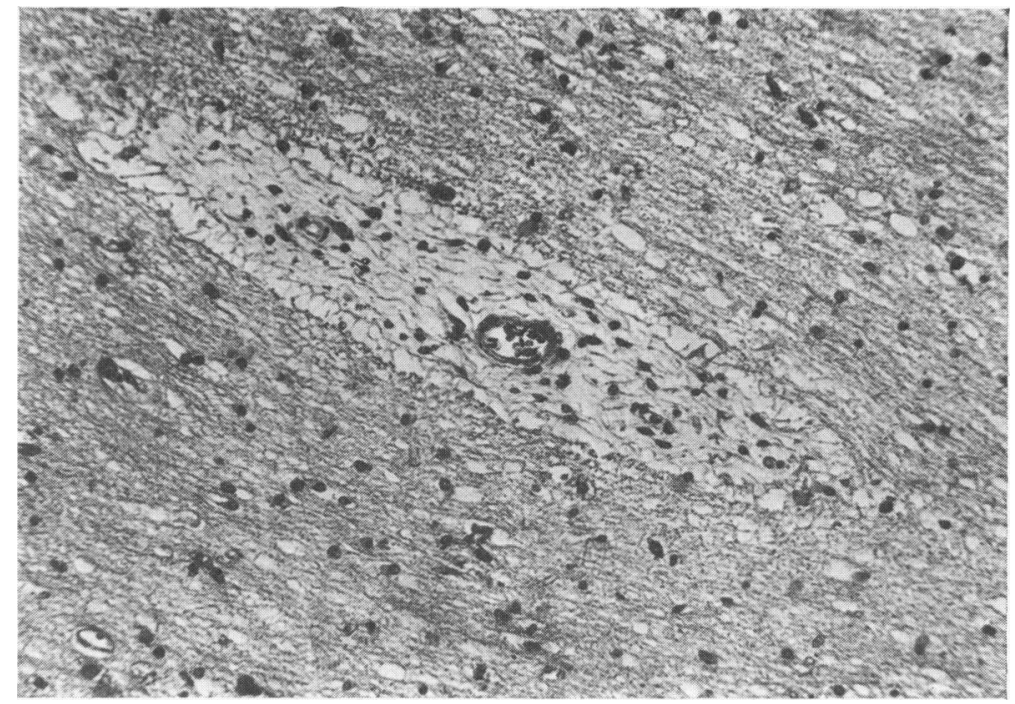

FIG. 8.-Cáse 2. Perivascular loss of myelin associated with glial overgrowth. (H.V.G. $\times 200$.) 


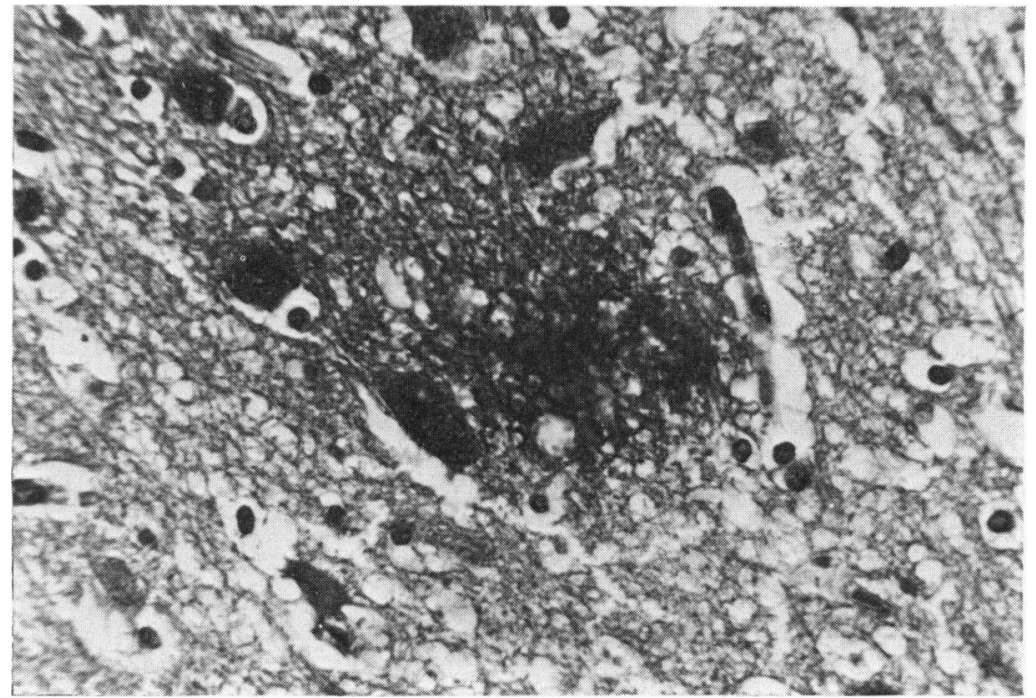

FIG. 9.-Case 2. A focus of coagulative necrosis around a capillary. (H. and E. $\times 375$.)

and the internal and external lemnisci. The medial longitudinal fasciculus also displayed fair myelination. The arcuate fibres were, on the whole, well myelinated, but not the intra-olivary and cerebello-olivary fibres. The myelinated portion of the restiform body was very thin.

There was marked loss of cerebellar Purkinje cells and proliferation of Bergmann glia. Although some myelinated fibres were present in the central and folial cerebellar white matter, their number was very reduced. As in the cerebral white matter, there was considerable glial proliferation. No certain neuronal loss was detected in the dentate nuclei, but the white matter surrounding it showed marked spongy degeneration.

The Eye. The stained section of the eye measured $1.5 \times 1.4 \mathrm{~cm}$. The lens, which had not been needled during life as in Case 1, showed generalized cataractous change, involving both the nucleus and the cortex. Some of the lamellae were lightly calcified.

The centre of the cataract was filled in part by fragmented eosinophil or granular material (Fig. 10). Many

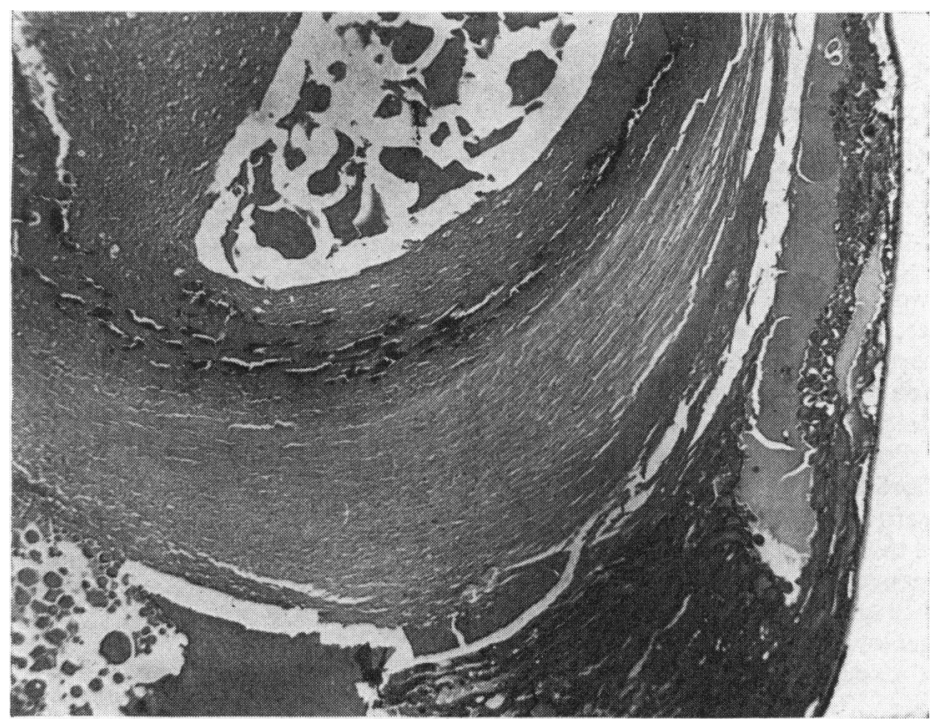

Fig. 10.-Case 2. Lamellation with partial calcification of the lens. The centre of the cataract is filled with fragmented debris. (H. and E. $\times$ 80.) 


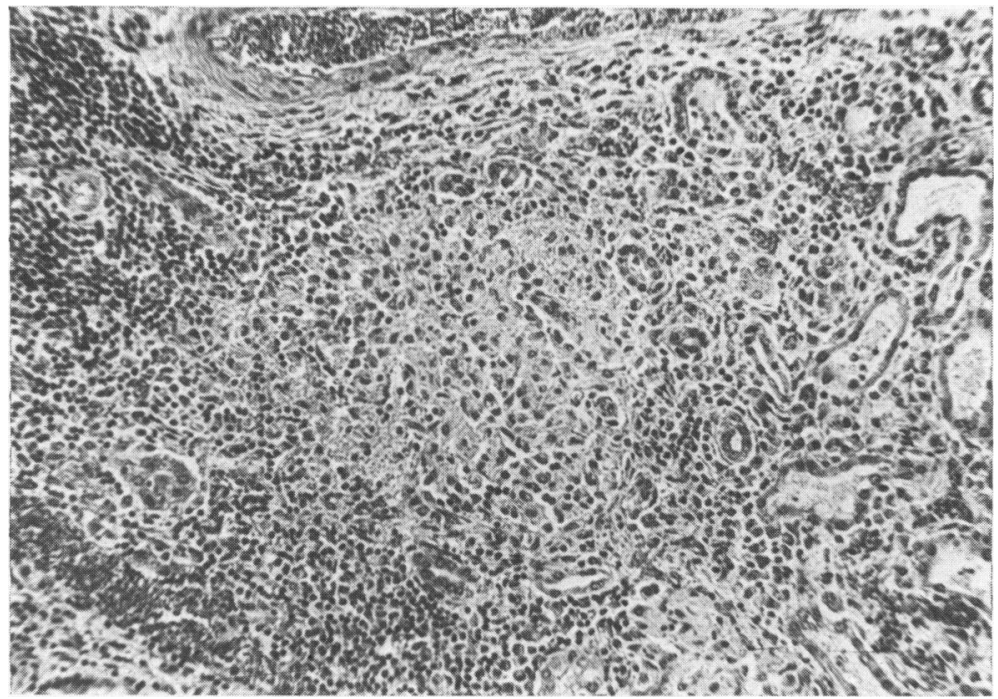

FIG. 11.-Cace 2. Necrotic area in the kidney situated in the outer zone of the medulla and partly surrounded by lymphocytes. (H. and E. $\times 200$.)

clefts and vacuoles were also present in the more distal parts of the lens. Some were 'empty' and others contained eosinophil reticular, granular or globular detritus. There were no synechiae, but the part of the lens capsule closest to the iris was covered externally by a layer of pigment. The canal of Schlemm was patent. A small cluster of lymphocytes was present on the internal aspects of the ciliary body. Other changes were as in Case 1.

Somatic Organs. Many necrotic lesions were present in the kidney (Fig. 11). Most of these were situated in the outer zone of the medulla, but some were also present in the cortex. Their size varied considerably and many were confluent. The central parts of the lesions showed coagulative necrosis, sometimes haemorrhagic, with or without a slight increase of lymphocytes and histiocytes. When cut tangentially, the lesions presented as areas of densely arranged lymphocytes and histiocytes placed upon a background of faintly outlined necrotic renal tissue. Polymorphs were scarce. Many tubules, particularly collecting ones, contained cellular, granular and fibrinous casts. Numerous small calcified particles were present in the convoluted tubules. Most of the glomeruli were normal but some showed glomerular fibrosis, swelling and proliferation of the cells of Bowman's capsules, or some fibrosis of the glomerular tufts. Arteries were often surrounded by a sleeve of lymphocytes and some showed thickening of their adventitia and intima. The above changes were present in one of the kidneys. A single available section from the other kidney contained no necrotic or 'pyelonephritic' lesions, but numerous calcified concretions were present in the convoluted tubules.

The lungs showed areas of multifocal collapse, inhalation pneumonia and early inflammatory change. Con- siderable siderosis and a few small haemorrhages were present in the spleen. Slight siderosis, cellular vacuolation and mild lymphocytic infiltration of portal tracts were present in the liver. The heart showed myocardial and endocardial oedema. The thyroid and pancreas were normal.

\section{Discussion}

The Marinesco-Sjögren Syndrome. This syndrome was first described in four sibs of a Roumanian family by Marinesco, Draganesco and Vasiliu (1931). Later, Sjögren (1950) traced 14 similar patients in Sweden, and examined four of these personally, presenting the detailed findings. He established that the condition was transmitted as an autosomal recessive character. There was a high rate of first cousin marriages among the ancestors of the patients in his series. A total of 18 further cases have since been recorded (Richards, 1950; Garland and Moorhouse, 1953; Franceschetti, Marty and Klein, 1956; MacGillivray, 1957; Doḡulu and Mutlu, 1957; Dureux, Cordier, Ziza and Tridon, 1958; Amyot, 1960; Blumel, Evans and Eggers, 1960; Poilici, Petrovici and Marinchescu, 1961), although not all of these are fully authenticated. Other, more doubtful, cases have been published by Gursdorf, Hécaen and Nau-Massonnet (1952), Dufour, Jéquier, Cuendet and Michels (1954), and Garcin, Raverdy, Delthil, Man and Chimenes (1961).

The chief features of the disease are mental retardation, signs of cerebellar involvement and 
cataracts. The cataracts have usually been described as 'congenital', but few of the publications give sufficient detail for precise classification. In many instances vision was normal in early life, the cataracts developing later. The age of the patients varied from 4 to 59 years, but most were adults. There was no difference in the sex incidence. Most patients were stunted in growth and some were distinctly microcephalic, although the head circumference was usually not recorded. Associated skeletal abnormalities were common. They included talipes, congenital dislocation of the hip, deformity of the thorax, genu valgum and delayed ossification of the phalanges. Epilepsy is mentioned in four of the records. Cerebellar involvement was manifested by ataxia, dysarthria, dysmetria and dysdiadokokinesis. Nystagmus was usually present but may have been partly due to blindness. There was no sensory disturbance, but pyramidal signs were very common. These included spastic pareses, briskness of tendon jerks and extensor plantar responses. On the other hand, tendon jerks could not be elicited in several cases.

Renal involvement has not been observed. The blood calcium was low in the original cases described by Marinesco et al. (1931), as well as in the father of their patients and in two of their otherwise normal sibs. The biochemical investigations of the two sisters, one 24 and the other 34 years of age, reported by Poilici et al. (1961), showed raised $\beta$ and $\gamma$ globulins and a marked decrease of many amino acids in the blood.

There are no recorded autopsy studies, but a biopsy was taken from the frontal lobe of one of their patients at 8 years by Marinesco et al. (1931). This showed a normal cytoarchitectonic pattern and good lamination of the cortex. Some Cajal cells were present in the marginal layer. There was slight neuronal sparsity in layer III (called layer IV, by the authors), and a certain tortuosity of the dendrites. Some of the neurones were considered to be abnormally large-'gigantocytose senile'. There were a few fat and pigment-containing phagocytes, and glial cells showed 'fatty degeneration'. Slight glial proliferation was present in the marginal layer. The blood vessels showed 'dilatation of the adventitia'. The myelin stained well but the fibres were somewhat rarefied.

Oculo-cerebro-renal (Lowe's) Syndrome. This condition was first described by Lowe, Terrey and MacLachlan (1952) in three unrelated boys, and nine further cases have since been reported (Bickel and Thursby-Pelham, 1954; Debré, Royer, Lestradet and Straub, 1955; Monnet, Matray and Etienne,
1955; Gérard-Lefebvre, Biserte, Woillez, Traisnel, Gosselin and Combaud, 1957; Denys, Corbeel, Eggermont and Malbrain, 1958; Schoen and Young, 1959; Dent and Smellie, 1961). The condition is often familial and there is strong evidence of sexlinkage. It seems to affect only boys and according to Donnell (1961), who referred to the study of five families in Los Angeles, male sibs have an equal chance of being affected. Donnell states that the condition is transmitted by female carriers and that the 'asymptomatic' heterozygous females show partial manifestation of the disease, viz. cataract or punctate opacities of the lens visible on slit-lamp examination. The presence of aminoaciduria had been reported in both the parents of one case (Debré et al., 1955), but the significance of this observation is uncertain.

The chief features of this syndrome are mental retardation, ocular involvement and renal disorder. Cataracts develop with or without glaucoma; the case reported by Monnet et al. (1955) presented with glaucoma only. Renal dysfunction is manifested by the presence of abnormal globulin in the urine, aminoaciduria and occasional glycosuria and acetonuria. There is systemic acidosis in some cases and a tendency to hypophosphataemia. The serum alkaline phosphatase may be raised. In a recent preliminary communication Schwartz, Hall and Gabuzda (1962) reported an abnormality in ornithine metabolism. Ossification may be delayed and there is a strong tendency to osteoporosis and rickets; the general growth is stunted, and in the one case where the size of the head circumference is stated there was microcephaly (Debré et al., 1955).

The mental development is usually grossly retarded but the neurological deficit does not appear to be as specific as in the Marinesco-Sjögren syndrome. Hyporeflexia and flabbiness have been usually mentioned among the clinical signs of the condition. Most of the patients were infants or young children, and none appears to have come to autopsy. However, a renal biopsy from one case was reported upon by Schoen and Young (1959). This kidney showed normal glomeruli, occasional multinucleate epithelial cells and unidentifiable crystalline material in the tubules. These findings were described as 'non-specific'. The results of electron microscopy were also of doubtful significance: swollen mitochondria in the tubular cells, with disruption of the mitochondrial cristae. The liver was substantially normal in a biopsy taken from their case by Bickel and Thursby-Pelham (1954).

Some atypical cases of 'oculo-cerebro-renal dystrophy' have also been reported. Of these, the account of two affected brothers by McCance, 
Matheson, Gresham and Elkington (1960) is of special interest, since it includes the only hitherto published autopsy findings. These patients failed to thrive after birth, one was definitely microcephalic, and both developed corneal opacities but not cataracts. The chief biochemical observations were uraemia, low blood sodium, high potassium, low total $\mathrm{CO}_{2}$, and a very acid urine of high specific gravity. The infants died at 4 and at 2 years. Pathologically, the cornea showed early keratinization and vascularization, a certain amount of calcification was present in the kidney, some of the superficial renal glomeruli were small and some of the nephrons dilated. The cerebral cortex was described as abnormal and there was marked cerebellar atrophy. These cases were not regarded by the authors as examples of Lowe's syndrome because of the absence of cataracts, aminoaciduria and osteoporosis, and because they presented, in contrast to Lowe's syndrome, uraemia and high urinary acidity.

The resemblance of some of the other published cases to Lowe's syndrome and to the present condition is even more remote (Sohar, 1954; Goldbloom, Fraser, Waugh, Aronovitch and Wiglesworth, 1957).

The Classification of the Present Cases. It is clear from the clinical and pathological data that the condition in the two present cases was identical, with only minor differences of renal and cerebral involvement. The family history is strongly suggestive of recessive autosomal inheritance. This, together with the presence of cataracts and encephalopathy, which would certainly have resulted in mental retardation had the patient lived longer, are points in favour of the Marinesco-Sjögren syndrome. Although, as mentioned above, a biopsy of the brain was taken in one of the previous cases, the findings are not really comparable; the patient was much older and relatively intelligent, the material was very limited and the histological methods unusual. On the other hand, the very brief survival of the present cases, the presence of renal involvement and particularly its unusual character, are out of keeping with the Marinesco-Sjögren syndrome.

The features favouring Lowe's syndrome are the presence of congenital cataracts, stunted growth, mental retardation and renal involvement. However, no aminoaciduria was detected in the one of the present cases tested for this condition, and the renal lesions were quite unlike those found in the one previously recorded biopsy. The short survival of the present cases is, perhaps, also against the diagnosis of Lowe's syndrome. Furthermore, unlike all previously reported cases, the patients were girls. There is no greater resemblance between the present cases and those mentioned above as 'atypical oculocerebrorenal dystrophy'. The cases of McCance et al. (1960) showed, like the present ones, cerebellar involvement, but the renal and ocular findings were quite different.

In view of the few reports of the MarinescoSjögren or Lowe's syndromes, and the virtual absence of pathological studies in either condition, it would be unwise to define them too rigidly. The present cases may yet prove to be variants of one of these syndromes, although the divergences outlined above appear substantial, suggesting another, hitherto undescribed, disease.

In this connexion it is of interest that Blumel, Ohnuki and Awa (1961) have reported an abnormality in one of the large chromosomes in a case suggestive of the Marinesco-Sjögren syndrome, which had been previously described by Blumel $e t$ al . (1960). It thus appears that further chromosomal studies, combined with metabolic, urinary and ophthalmic investigations of similar patients and their relatives might help to clarify the nosological situation and the aetiology of the condition.

\section{Summary}

Two infant sisters presented congenital cataracts, epileptic fits, mental deficiency and small stature. One died at 4 months, the other at 8 months. The post-mortem findings were identical in both cases; encephalopathy, renal tubular necrosis and cataracts. The condition resembles both the MarinescoSjögren and the Lowe's syndromes, but could also be an instance of another, hitherto undescribed, disease.

We are grateful to Professor R. C. Curran for the paraffin blocks of Case 1, and to Dr. A. G. Stansfeld for permission to use his post-mortem findings and material of Case 2. Professor N. Ashton and Dr. K. Porter have kindly verified some of our histological findings, and Dr. Seymour Mason, has helped with the clinical examination of members of the family. Professor P. I. Polani kindly arranged the chromosome examination of IV 3

\section{REFERENCES}

Amyot, R. (1960). Le syndrome de Marinesco-Sjögren. Revue de la littérature. Trois observations personelles portant sur trois soeurs. Rev. neurol., 103, 97.

Bickel, H. and Thursby-Pelham, D. C. (1954). Hyperamino-aciduria in Lignac-Fanconi disease, in galactosaemia and in an obscure syndrome. Arch. Dis. Childh., 29, 224.

Blumel, J., Evans, E. B. and Eggers, G. W. N. (1960). A combination of congenital cataract and cerebral palsy in a brother and a sister. Arch. Ophthal., 63, 246.

- Ohnuki, Y. and Awa, A. (1961). Chromosome anomaly in two cases of cerebral palsy, a brother and a sister. Nature (Lond.), $189,154$.

Debré, R., Royer, P., Lestradet, H. and Straub, W. (1955). L'Insuffisance tubulaire congénitale avec arriération mentale, cataracte et glaucome (Syndrome de Lowe). Arch. franc. Pédiat., 12, 337. 
Dent, C. E. and Smellie, J. M. (1961). Two children with oculocerebro-renal syndrome of Lowe, Terrey and MacLachlan. Proc. roy. Soc. Med., 54, 335.

Denys, P., Corbeel, L., Eggermont, E. and Malbrain, H. (1958). Le Syndrome de Lowe. Étude de la fonction tubulaire. Pédiatrie, 13, 639.

Doḡulu, S. and Mutlu, N. (1957). Iki kardeste konjenital katarakt, spinoserebellar ataksia ve oligofrenia Deniz Tip Bül., 3, No. 4, p. 1 .

Donnell, G. N. (1961). Children with oculo-cerebro-renal syndrome of Lowe, Terrey and MacLachlan. Proc. roy. Soc. Med., $54,336$.

Dufour, R., Jéquier, M., Cuendet, J. F. and Michels, V. (1954). Cataracte et oligophrénie. Bull. et Mémoires Soc. franc. Ophtal. 67,318 .

Dureux, J. B., Cordier, J., Ziza, P. and Tridon, P. (1958). Hérédoataxie, cataracte et oligophrénie (Syndrome de MarinescoSjögren). Rev. neurol., 98, 777.

Franceschetti, A., Marty, F. and Kiein, D. (1956). Un syndrome rare: hérédoataxie avec cataracte congénitale et retard mentale. Confin. neurol. (Basel), 16, 271.

Garcin, R., Raverdy, P., Delthil, S., Man, H. X. and Chimenes, H. (1961). Sur une affection hérédo-familiale associant cataracte, atrophie optique, signes extra-pyramidaux et certains stigmates atrophie optique, signes extra-pyramidaux et certain
de la maladie de Friedreich. Rev, neurol., 104, 373.

Garland, H. and Moorhouse, D. (1953). An extremely rare recessive hereditary syndrome including cerebellar ataxia, oligophrenia, cataract, and other features. J. Neurol. Neurosurg. Psychiat., 16, 110 .

Gérard-Lefebvre, Biserte, G., Woillez, M., Traisnel, M., Gosselin, J. and Combaud, A. (1957). Étude clinique, génétique et biologique du syndrome de Lowe-Bickel. Pédiatrie, 12, 527.

Goldbloom, R. B., Fraser, R. C., Waugh, D., Aronovitch, M. and Wiglesworth, F. W. (1957). Hereditary renal disease associated with nerve deafness and ocular lesions. Pediatrics, 20, 241.
Gursdorf, C., Hécaen, H. and Nau-Massonnet, M. (1952). Communication à propos de la maladie de Sjögren. Ann. méd.psychol., 110(1), 65.

Lowe, C. U., Terrey, M. and MacLachlan, E. A. (1952). Organicaciduria, decreased renal ammonia production, hydrophthalmos, and nental retardation. A.M.A. Amer.J. Dis. Child., 83, 164

McCance, R. A. Matheson, W. J., Gresham, G. A. and Elkington, J. F. (1960). The cerebro-ocular-renal dystrophies: A new variant. Arch. Dis. Childh., 35, 240.

MacGillivray, R. C. (1957). Oligophrenia, cerebellar ataxia and cataract. The syndrome of Marinesco-Garland. Amer. J. ment. Defic., 61, 719.

Marinesco, G., Draganesco, St. and Vasiliu, D. (1931). Nouvelle maladie familiale caractérisée par une cataracte congénitale et un arrêt du développement somato-neuro-psychique. Encéphale, 26, 97.

Monnet, P., Matray, and Etienne (1955). Glaucome congénitale et néphropathie. Pédiatrie, 10, 617.

Poilici, I., Petrovici, I. and Marinchescu C. (1961). The MarinescoSjögren-Garland syndrome. A report of two cases. Psychiat. et Neurol. (Basel), 142, 404 .

Richards B. W. (1950). Cataracts, ataxia and mental deficiency: a report of two cases. J. ment. Sci.,96, 537.

Schoen, E. J. and Young G. (1959). 'Lowe's syndrome.' Abnormalities in renal tubular function in combination with other congenital defects. Amer. J. Med., 27, 781 .

Schwartz, R., Hall. P. W. and Gabuzda, G. J. (1962). The metabolism of ornithine and other amino acids in the cerebro-oculo-renal syndrome. Amer. J. Dis. Child., 104, 484.

Sjögren, T. (1950). Hereditary congenital spinocerebellar ataxia accompanied by congenital cataract and oligophre and clinical investigation. Confin. neurol. (Basel), 10, 293.

Sohar, E. (1954). A heredo-familial syndrome characterized by renal disease, inner ear deafness and ocular changes. Harefuah, 47,161 . 